\title{
Prone position improves expiratory airway mechanics in severe chronic bronchitis
}

\author{
S.D. Mentzelopoulos*, C. Roussos ${ }^{\#}$ and S.G. Zakynthinos ${ }^{\#}$
}

ABSTRACT: Based on lung parenchyma-airways' interdependence, the present authors hypothesised that prone positioning may reduce airway resistance in severe chronic bronchitis.

A total of 10 anaesthetised/mechanically ventilated patients were enrolled. Partitioned respiratory system (RS) mechanics during iso-flow experiments (flow $=0.91 \mathrm{~L} \cdot \mathrm{s}^{-1}$, tidal volume (VT) varied within 0.2-1.2 L), haemodynamics, gas-exchange, expiratory airway resistance (Raw,exp), functional residual capacity (FRC), change in FRC ( $\triangle F R C$ ), end-expiratory lung volume (EELV), expiratory airway resistance at EELV (Raw,exp,EELV), intrinsic positive end-expiratory pressure (PEEPi), and mean end-expiratory flow were determined in baseline semirecumbent (SRBAS), prone, and post-prone semirecumbent (SRPP) postures.

Pronation versus SRBAS resulted in significantly reduced $R$ aw,exp (at $V_{T} \geqslant 0.8 \mathrm{~L}$ ), Raw,exp,EELV $\left(18.3 \pm 1.4\right.$ versus $31.6 \pm 2.6 \mathrm{~cm} \mathrm{H}_{2} \mathrm{O} \cdot \mathrm{L}^{-1} \cdot \mathrm{s}^{-1}$ ), inspiratory airway resistance (at $V_{\mathrm{T}} \geqslant 1.0 \mathrm{~L}$ ), static lung elastance (at $V_{T} \leqslant 0.6 \mathrm{~L}$ ), "additional" $\mathrm{RS} /$ lung resistance (at a range of $\left.\mathrm{VTS}\right), \Delta \mathrm{FRC}(0.35 \pm 0.03$ versus $0.47 \pm 0.03 \mathrm{~L}$ ), EELV (4.92 \pm 0.49 versus $5.65 \pm 0.65 \mathrm{~L})$, RS/lung PEEPi $(6.7 \pm 1.1 / 5.4 \pm 0.6$ versus $\left.8.9 \pm 1.7 / 7.8 \pm 1.1 \mathrm{~cm} \mathrm{H}_{2} \mathrm{O}\right)$, mean end-expiratory flow $\left(63.9 \pm 4.2\right.$ versus $\left.47.9 \pm 4.0 \mathrm{~mL} \cdot \mathrm{s}^{-1}\right)$, and shunt fraction $(0.16 \pm 0.03$ versus $0.21 \pm 0.03)$; benefits were reversed in SRPP.

In severe chronic bronchitis, prone positioning reduces airway resistance and dynamic hyperinflation.

KEYWORDS: Air flow, airway resistance, chronic obstructive pulmonary disease, compliance, mechanical ventilation

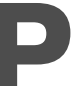
ronation of chronic obstructive pulmonary disease (COPD) patients improves lung parenchyma mechanics and arterial oxygenation [1]. Lung inflation gradient is attenuated $[1,2]$ and lung compression by the heart is eliminated [1, 3]. Regional alveolar ventilation may become more homogenous [1, 4], suggesting reduction in alveolar atelectasis and hyperinflation [1]. Decreased atelectasis and more uniform inflation should result in more homogenous and increased average alveolar septal tension [5]; the latter is transmitted to airway walls via connective tissue cables [5], resulting in outward wall traction and airway calibre increase [6]. If parenchymal elastic recoil is "maintained" (e.g. chronic bronchitis) [6, 7], pronation might enhance "parenchyma-induced bronchodilation".

In severe chronic bronchitis [8], bronchial wall inflammation/hypertrophy leads to airway stenosis [6]; increased mucosal thickness may augment airway obstruction reversibility with "effective bronchodilation" [6]. However, severe COPD patients may be unresponsive to brochodilator drugs [9]; in such patients, alternative mechanisms of increasing airway calibre may become important. Severe COPD is characterised by increased airway resistance and intrinsic positive end-expiratory pressure (PEEPi) $[10,11]$.

The present authors theorised that in severe chronic bronchitis, prone position versus semirecumbent may reduce airway resistance. The current authors also sought to determine any pronation benefits on dynamic pulmonary hyperinflation. PEEPi, functional residual capacity (FRC), change in FRC $(\triangle \mathrm{FRC}$; where $\triangle \mathrm{FRC}=$ increment in FRC reflecting dynamic hyperinflation), end-expiratory lung volume (EELV; where $E E L V=F R C$ plus $\triangle F R C)$, and mean endexpiratory flow $\left(V^{\prime}\right)$ were also comparatively assessed in the prone and semirecumbent positions.

\section{MATERIAL AND METHODS \\ Patients}

Institutional Review Board (Evaggelismos General Hospital, Scientific Committee, Athens, Greece) approval and patient/next-of-kin consent were obtained. A total of 10 severe chronic bronchitis patients (table 1) [8,9] were enrolled. Patients were positioned semirecumbent,

\section{AFFILIATIONS}

*University of Athens Medical School, Dept of Intensive Care Medicine, Attikon University Hospital and

\#University of Athens Medical School, Dept of Intensive Care Medicine, Evaggelismos General Hospital, Athens, Greece.

CORRESPONDENCE

S.D. Mentzelopoulos 12 Ioustinianou Street GR-11473

Athens

Greece

Fax: 302103218493

E-mail: sdm@hol.gr

Received:

August 122004

Accepted after revision:

September 302004

SUPPORT STATEMENT

The present work was funded solely by the Dept of Intensive Care Medicine, University of Athens Medical School, Evaggelismos General Hospital, Athens, Greece. 


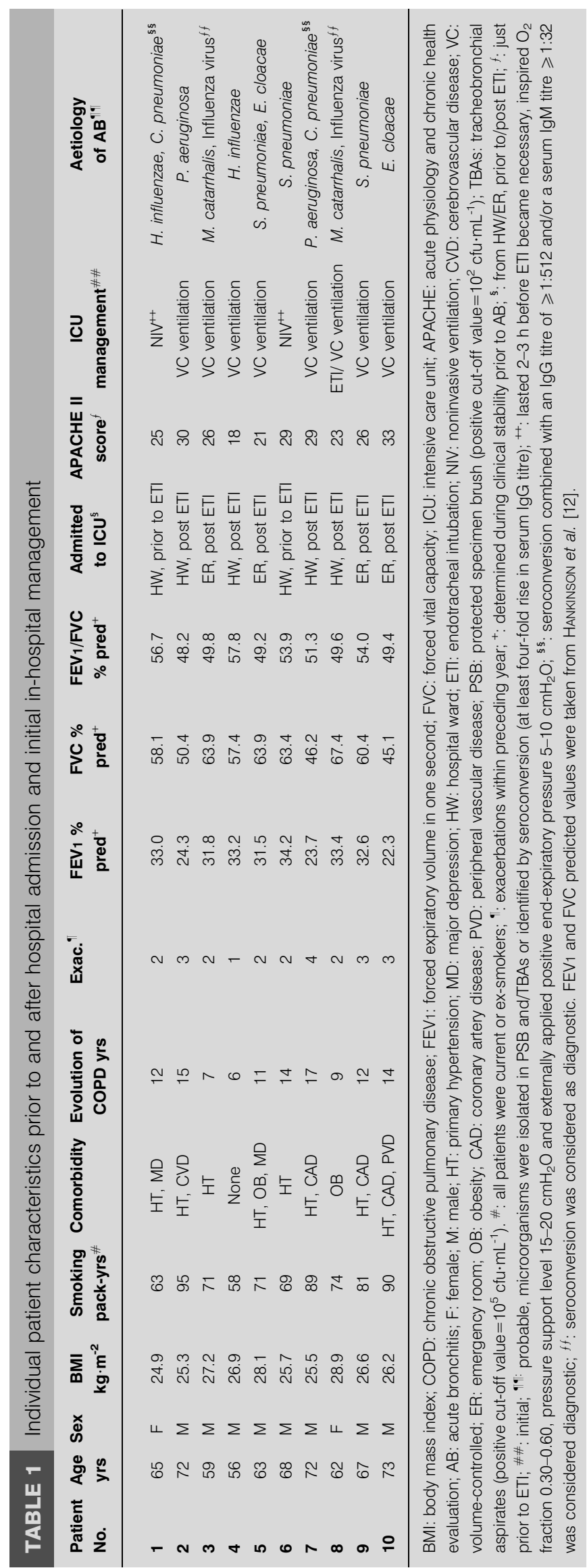

orotracheally intubated and mechanically ventilated (Siemens 300C ventilator; Siemens AG, Berlin, Germany). All patients were admitted to the intensive care unit because of acute respiratory failure (arterial oxygen tension $\left(\mathrm{Pa}, \mathrm{O}_{2}\right) /$ inspiratory oxygen fraction $\left(\mathrm{FI}, \mathrm{O}_{2}\right), 82-135 \mathrm{mmHg}$; carbon dioxide arterial tension $\left.\left(\mathrm{Pa}_{\mathrm{a}} \mathrm{CO}_{2}\right), 72.8-112.6 \mathrm{mmHg}\right)$ secondary to acute bronchitis, defined as in DEWAN et al. [13]. There were no patients with an already existing tracheostomy. The duration of mechanical ventilation until study protocol initiation ranged 32.4-46.5 h. Patients were poor responders to bronchodilators $[7,9]$ during the pre-admission period of clinical stability. Previously published exclusion criteria [1] were applied. During the 7.0-7.5-h study period, patient care was provided by a physician not involved in the present study. Monitoring was as previously described [1]. Any enteral nutrition was replaced by parenteral administration, gastric contents were suctioned, and the nasogastric tube was removed. Anaesthesia was induced with propofol/fentanyl and maintained throughout the study period with propofol/fentanyl infusions to achieve respiratory muscle inactivity $[14,15]$.

\section{Inspiratory $V^{\prime}$, tidal volume, and tracheal, oesophageal and gastric pressures}

Inspiratory $V^{\prime}$, tidal volume $(V \mathrm{~T})$, tracheal, oesophageal and gastric pressures ( $P$ aw, $P$ oes and $P$ ga, respectively) were measured with heated pneumotachograph (pneumotachometer; Hans Rudolph Inc., Kansas City, MT, USA) and Validyne pressure-transducers (Validyne, Nortridge, CA, USA) [1, 16]. Correct oesophageal and gastric balloon positioning were verified before anaesthesia induction as previously described [17-19]. Following analogue-to-digital conversion, variable data were stored on an IBM-type computer for later analysis with Anadat software (RHTInfoData, Montreal, QC, Canada). During data sampling, variable tracings were displayed on a dedicated monitor and recorded with an eight-channel electrostatic recorder (Gould ES 1000; Gould Electronics Inc., Eastlake, OH, USA). Breathing circuit modifications included removal of humidifier and use of low compliance tubing [16]. A manually operated, pneumatically driven valve (Hans-Rudolph 9300) was inserted between the pneumotachograph and ventilator's Y-piece. Care was taken to avoid gas leaks. Equipment dead space (endotracheal tube not included) was $130 \mathrm{~mL}$.

Respiratory mechanics were sequentially assessed with constant $V^{\prime}$ rapid airway occlusion in baseline semirecumbent (SRBAS, $60^{\circ}$ inclination), prone, and post-prone semirecumbent (SRPP, $60^{\circ}$ inclination) positions. Patient turning was performed as previously completed [1]. Following pronation, abdominal movement restriction was minimised by placing a roll under the upper part of the chest wall and a pillow under the pelvis $[1,2]$. The reliability of $P_{\text {oes }}$ measurements was tested as previously described [1]. Figure 1 presents data originating from a representative study participant.

Figure $1 \mathrm{~d}$ shows a Poes tracing which constitutes the average of Poes tracings of all four sigh-breaths. All other tracings originate from the second of the four test sighs. The Poes tracing in figure 1e shows the maximal amplitude of cardiac oscillation $=P$ peak $-P$ plateau; and $P$ oes rise rate during cardiac oscillation $=$ time needed for $P$ oes to rise from $P$ plateau to $P$ peak. For each set of test breaths, cardiac oscillation variables were 


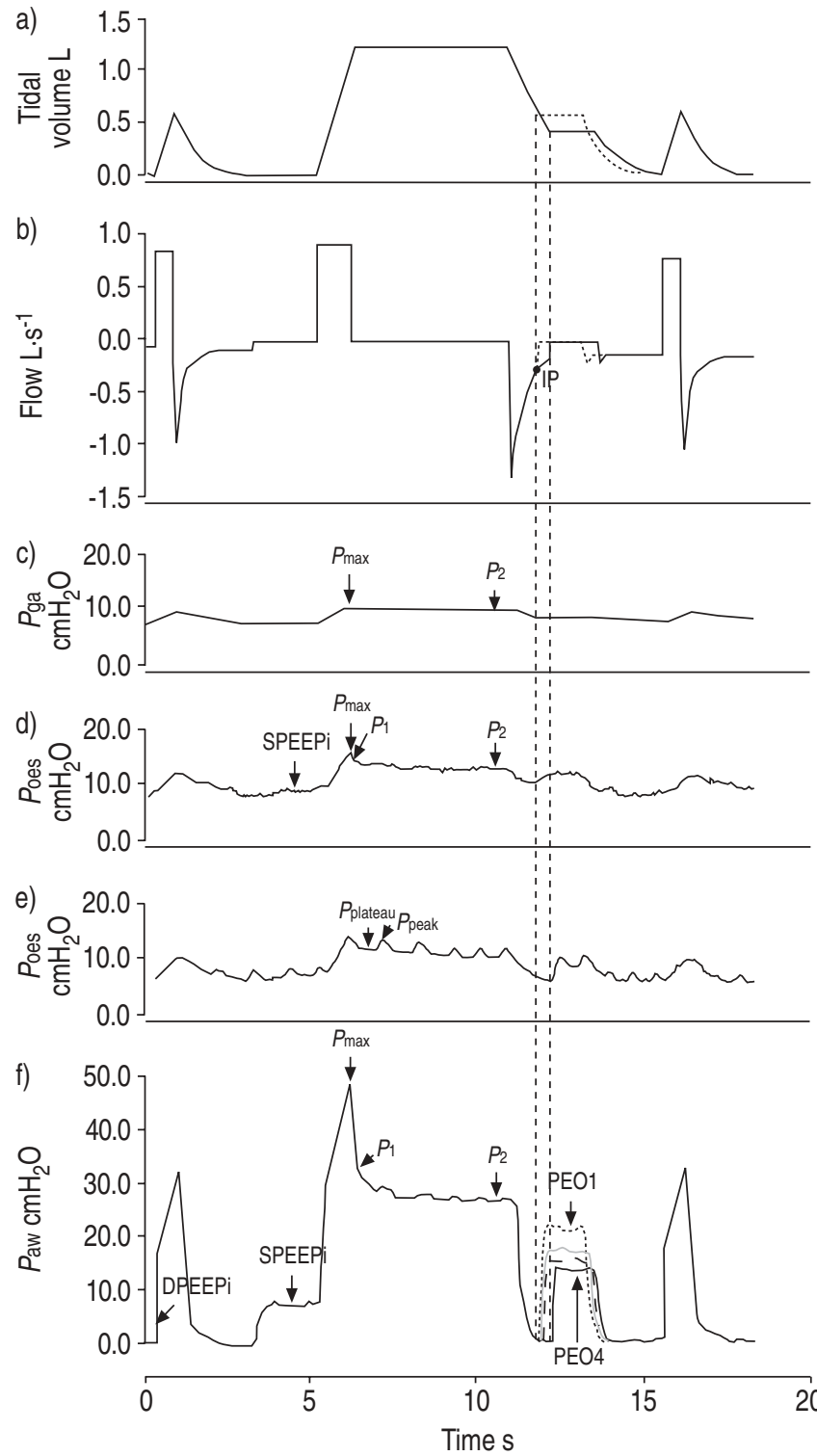

FIGURE 1. Methodology of assessment of respiratory mechanics. a) Tidal volume, b) flow, and c) gastric, $d$ and e) oesophageal and f) tracheal pressures ( $P$ ga, $P$ oes and $P$ aw, respectively) data print-out, showing two baseline ventilation breaths separated by a sigh test breath $(\mathrm{V} T=1.2 \mathrm{~L})$, an expiratory occlusion tracing of $P$ aw, and three superimposed expiratory occlusion tracings originating from the rest three breaths of the set. f) The Paw tracings of the expiratory occlusions of the three test sighs $(---, \cdots \cdot$ and grey line) at rest were superimposed according to their time lag relative to inflection point (IP). Expiratory occlusion pressure (PEO) 1 is the earliest expiratory occlusion relative to IP. The long dashed lines were drawn from the start of the earliest (dashed line) and latest expiratory occlusion Paw tracings, and enclose an expired tidal volume slice, during which the dynamic deflation compliance of the respiratory system was determined. Deflation compliance was approximately constant during all studied volume slices. Pmax: peak inspiratory pressure; DPEEPi: dynamic intrinsic positive end-expiratory pressure (PEEPi); SPEEPi: static PEEPi; $P$ peak: peak pressure; Pplateau: plateau pressure; $P 1$ : pressure immediately after end-inspiratory airway occlusion; $P 2$ : plateau inspiratory pressure.

averaged and compared among study postures, in order to assess the reliability of Poes measurements. The test breath is followed by an expiratory occlusion (continuous black line; fig. 1), during which expiratory occlusion pressure 4 was determined. This occlusion was the most delayed in all four test-sighs relative to the expiratory flow inflection point.

Table 2 displays baseline ventilator settings employed throughout the study period. Interventions (below described) were separated by 15-min periods of baseline ventilation for reestablishment of baseline conditions [20]. Within 30-60 min after study-posture assumption, six sets of four test breaths were administered. In the sets of test breaths a constant, square-wave, inspiratory $V^{\prime}\left(0.91 \mathrm{~L} \cdot \mathrm{s}^{-1}\right)$ was employed. For the first, second, third, fourth, fifth and sixth set of test breaths, the respective administered $V$ Ts were $0.2,0.4,0.6$ (baseline), 0.8, 1.0, and 1.2 ("sigh" [21]) L. Test breaths were separated by 1min baseline ventilation. Maximal allowable plateau airway pressure $(P 2, \mathrm{aw})$ was $50 \mathrm{cmH}_{2} \mathrm{O}$.

Test breaths were preceded by 2-s duration end-expiratory occlusions, enabling determination of static respiratory system (RS) PEEPi, chest wall PEEPi, and abdominal chest wallcomponent PEEPi (fig. 1) [1]; the latter was always $\sim 0$. For Poes, end-expiratory occlusion-plateaus were obtained by ensemble averaging [22] of Poes tracings of each test breath set (fig. 1). Dynamic PEEPi was defined as Paw change generating inspiratory $V^{\prime}$ and initiating lung inflation [23]. Dynamic PEEPi was determined at baseline ventilation breaths that preceded test breaths (fig. 1). Expiratory occlusions were followed by 4-6-s duration end-inspiratory occlusions, enabling determination of maximal pressure $(P \max )$, pressure immediately after initiation of end-inspiratory occlusion $\left(P_{1}\right)$, and plateau pressure $\left(P_{2}\right)$ on computer-stored $P$ aw tracings, and of $P$ max and $P_{2}$ on computer-stored $P$ ga tracings (fig. 1). For $P_{\text {oes, }} P_{\max }, P_{1}$, and $P_{2}$ were determined after ensemble averaging of the tracings of each set of test breaths [22] (fig. 1). $P$ aw values were referred to atmospheric pressure, and Poes/ $P$ ga values were referred to their pre-end-expiratory occlusion values [1]. For each set of test breaths, transpulmonary pressure $(P \mathrm{~L})$ was determined as difference between average $P$ aw value and averaged $P$ oes.

\section{Haemodynamics and gas exchange}

Within 75-90 min of study-posture assumption, thermodilution cardiac output (in triplicate), central venous and pulmonary artery wedge pressures, heart rate, mean arterial and

TABLE 2 Baseline ventilator settings employed throughout the study period

Ventilator mode

Volume-controlled

Inspired $\mathrm{O}_{2}$ fraction

$0.35-0.60$

Inspiratory flow $L \cdot \mathrm{s}^{-1}$

$0.91 \pm 0.02$

Tidal volume $\mathrm{L}$

Breathing rate cycles $\cdot \mathrm{min}^{-1}$

$0.6 \pm 0.02$

Inspiratory time-to-total respiratory cycle ratio

$18.0 \pm 0.7$

Expiratory time s

$0.20 \pm 0.01$

External positive end-expiratory pressure $\mathrm{cmH}_{2} \mathrm{O}$

$2.7 \pm 0.5$

Plateau pressure time s

0

Data are presented as range, mean \pm SD or value. 
pulmonary artery pressures, and gas exchange variables were determined/recorded as previously described [1]. Formuladerived variables included cardiac, systemic, and pulmonary vascular resistance index, oxygen consumption, respiratory quotient, alveolar oxygen partial pressure, and shunt fraction (see Appendix 1).

\section{Inspiratory resistance and elastance}

Total respiratory system, chest wall, and lung inspiratory mechanical properties were computed by standard formulas (see Appendix 2) [1].

\section{Expiratory airway resistance}

Monitor-displayed expiratory $V^{\prime}$ waveforms exhibited an inflection point, $\sim 1 \mathrm{~s}$ following the release of inspiratory occlusion (fig. 1). Inflection point was defined as point of maximum change in curve-slope following expiratory peak $V^{\prime}$ (fig. 1) [15]. Expiratory Paw was determined during 2-s duration expiratory occlusions performed with the pneumatically driven valve within $1 \mathrm{~s}$ following inflection point's appearance (fig. 1). Each expiratory occlusion was followed by a 2-s duration endotracheal tube disconnection from breathing circuit, in order to achieve a nonoccluded expiratory period approximately equal to baseline ventilation's expiration time (table 2).

For each set of post-test breath expirations, RS dynamic deflation compliance was assumed as identical at any expiration time point from test $V \mathrm{~T}$ to EELV. This would mean identical expiratory occlusion pressure at any expiration time point, corresponding to identical RS volume, and should allow superimposition of $P$ aw tracings of each test breath-set (fig. 1). The aforementioned assumption was supported by the following facts: 1) test breaths were separated by 1-min periods of baseline ventilation with identical $V \mathrm{~T}$ and inspiratory $V^{\prime}$, resulting in identical $P$ aw $/ P$ oes changes; thus, pre-test breath $V \mathrm{~T}$ history and corresponding pressure changes were identical; 2) just prior to inspiratory occlusion release, $P_{2}$,aw values, representing initial, expiratory driving pressure were identical; and 3) lung emptying pattern was virtually identical, as confirmed by analysis of expiratory $V^{\prime}$ and expired $V \mathrm{~T}$ tracings.

For each set of test breaths, the Paw tracing with the most delayed (relative to inflection point) expiratory occlusion (reference $P$ aw tracing) was used for determination of expiratory airway resistance (Raw,exp). Expiratory occlusion portions of the rest three $P$ aw tracings were superimposed on the reference $P$ aw tracing (fig. 1). Subsequently, lines were drawn from the onset of the earliest and latest expiratory occlusion towards the expiratory $V^{\prime} V \mathrm{~T}$ tracings (fig. 1). These lines enclosed expired $V \mathrm{~T}$ slices of $0.05-0.15$ L. For each $V \mathrm{~T}$ slice, deflation time constant was defined as the time needed for expiration of the initial $63 \%$ portion of that particular $V \mathrm{~T}$ slice. For each $V$ T slice, RS dynamic deflation compliance was determined as $V$ T changes divided by respective $P$ aw changes (fig. 1). Raw,exp was computed as VT-slice time constant divided by RS dynamic deflation compliance.

\section{$\triangle F R C, F R C$ and end-expiratory lung volume}

At $105 \mathrm{~min}$ following study-posture assumption, baseline ventilation $\triangle F R C$ was measured by allowing exhalation to
FRC (fig. 2) [16]. Immediately thereafter, FRC was determined with the closed-circuit helium dilution technique [2, 24, 25]. An anaesthesia bag filled with $2.0 \mathrm{~L}$ of $13 \%$ helium in oxygen was connected to the airway opening, and 20 deep manual breaths were administered at a rate of 4 cycles $\cdot \mathrm{min}^{-1}$. Helium concentration in the anaesthesia bag was measured with a helium dilution analyser (PK Morgan Ltd., Kent, UK). FRC was computed as follows:

$$
\mathrm{FRC}=\mathrm{V}_{\mathrm{i}}[\mathrm{He}]_{\mathrm{i}}[\mathrm{He}]_{\mathrm{fin}}{ }^{-1}-\mathrm{V}_{\mathrm{i}}
$$

where $V \mathrm{i}=$ initial gas volume in the anaesthesia bag, and [He]i and [He]fin are the initial and final helium bag concentrations, respectively. EELV was computed as FRC plus $\triangle F R C$. Baseline ventilation was resumed for $15 \mathrm{~min}$, the endotracheal tube was clamped during an end-expiratory occlusion, and baseline ventilation EELV was determined as described above. $\triangle F R C$ was computed as the helium dilution EELV-FRC difference. The reliability of the helium dilution technique [26] was assessed by comparing measured and computed $\triangle F R C$ and EELV.

\section{Expiratory airway resistance at EELV (Raw,exp,EELV) and mean end-expiratory $V^{\prime}$}

Computer-stored tracings of flow and volume during measurement of change in FRC in a representative study participant placed in the SRPP position is shown in figure 2 . The expiratory flow corresponding to the EELV point of exhaled volume was determined. At this point, the driving pressure was considered as equal to dynamic intrinsic PEEPi. Expiratory resistance at EELV was then determined by dividing dynamic PEEPi by expiratory flow at EELV (fig. 2). $\triangle \mathrm{FRC}$ reflects dynamic hyperinflation, and corresponds to the terminal portion of expiration [1, 14], during which expiratory

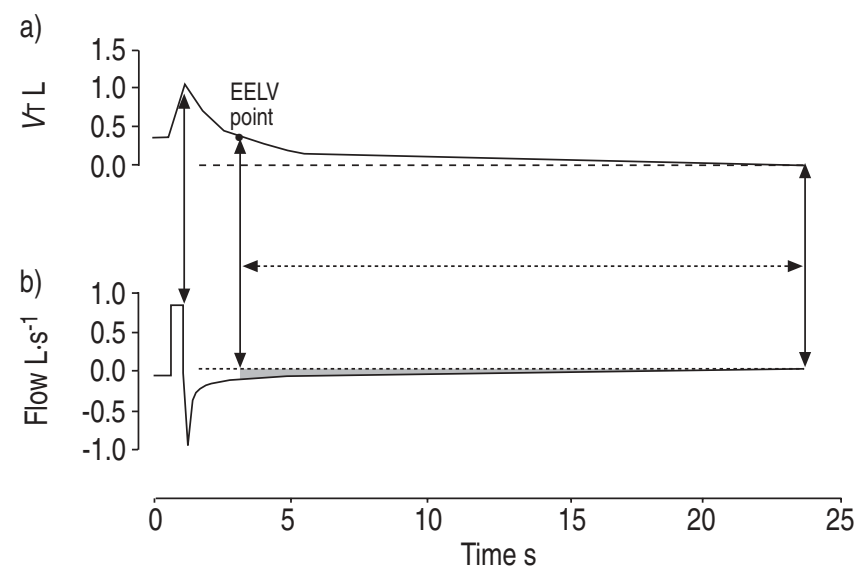

FIGURE 2. Methodology of determination of expiratory resistance at endexpiratory lung volume (EELV), and mean end-expiratory flow. Change $(\Delta)$ in functional residual capacity (FRC) expiration was defined as expiration from EELV to respiratory system relaxation volume (dotted arrow); respiratory system relaxation volume (- - ) coincides with FRC. Mean end-expiratory flow during $\triangle \mathrm{FRC}$ expiration was determined by dividing the grey shaded flow-time surface area (enclosed by the expiratory flow tracing, and the zero flow line: ..... shown in b) by the number of seconds corresponding to the duration of $\triangle F R C$ expiration. The duration of baseline tidal volume-to-EELV expiration is the time period corresponding to the interval between the first and second vertical arrows. $V_{T}$ : tidal volume. 
$V^{\prime}$ limitation is present [15]. Thus, during $\triangle \mathrm{FRC}$ expiration, increases in expiratory driving pressure do not affect expiratory $V^{\prime}[27,28]$. Expiratory $V^{\prime}$ limitation is due to excessive expiratory airway narrowing [29]. An increase in expiratory $V^{\prime}$ during the $V^{\prime}$-limited portion of expiration and a reduced duration of the latter expiration portion would indicate less expiratory airway narrowing and attenuation of expiratory $V^{\prime}$ limitation. Mean end-expiratory $V^{\prime}$ during $\triangle \mathrm{FRC}$ expiration were determined as shown in figure 2. The duration of "baseline VT-to-EELV" expiration (initial phase of passive expiration) was also determined (fig. 2).

\section{Statistical analysis}

For each posture, apart from single measurements (FRC, EELV, $\triangle F R C)$, only means of obtained sets of measurements were analysed. Variable comparisons were conducted with twofactor univariate ANOVA for repeated measures, followed by the Scheffé test as appropriate. Significance was accepted at $\mathrm{p}<0.05$. Values are presented as mean $\pm \mathrm{SD}$ or grand mean $^{*} \pm \mathrm{SD}$.

\section{RESULTS}

Full data were obtained from all patients, and no protocolrelated complications [1] occurred. Pga was unaffected by posture change (data not shown). Mean maximal amplitude of "cardiac oscillations" in Poes $\left(2.1^{*} \pm 0.8 \mathrm{cmH}_{2} \mathrm{O}\right)$ and mean Poes-rise rate during these oscillations $\left(10.2^{*} \pm 3.7 \mathrm{cmH}_{2} \mathrm{O} \cdot \mathrm{s}^{-1}\right)$, and absolute Poes at EELV $\left(11.8^{*} \pm 3.2 \mathrm{cmH}_{2} \mathrm{O}\right)$ were similar in all study postures. Consequently, the initial, correct positioning of the oesophageal balloon relative to the heart was maintained throughout the study period [1]. Respiratory cycleinduced changes in Poes were measured as accurately as possible in all study postures, and their comparability among these postures was "adequate" [1, 2, 24, 25, 30].

\section{Inspiratory mechanics}

The main results on partitioned inspiratory mechanics are presented in figure 3.

Additional RS resistance was significantly lower in prone versus SRBAS at all test $V$ Ts. Static chest wall elastance $(E$ stat,cw), was higher in prone versus SRBAS at all test VTs. Maximal and interrupter (Rint,Lung) lung resistance were lower in prone versus SRBAS at $V$ Ts $\geqslant 1.0 \mathrm{~L}$. Additional lung resistance ( $\Delta R$ Lung) was lower in prone versus SRBAS at all test $V$ Ts. Dynamic and static (Estat,Lung) lung elastance were lower in prone versus SRBAS at $V$ Ts $\leqslant 0.6 \mathrm{~L}$. All other determined variables were unaffected by posture change. $V$ T dependence of inspiratory mechanics was virtually unaffected by posture change.

\section{Haemodynamics and gas exchange}

Haemodynamics and gas exchange during baseline ventilation are shown in table 3.

Haemodynamic variables were unaffected by posture change. Pronation resulted in higher $\mathrm{Pa}_{2} \mathrm{O}_{2} /$ inspired $\mathrm{O}_{2}$ fraction $\left(\mathrm{Pa}, \mathrm{O}_{2} /\right.$ $\left.\mathrm{FI}_{1} \mathrm{O}_{2}\right)$ and lower shunt fraction versus SRBAS.

\section{PEEPi, $\triangle F R C$, FRC and EELV}

Dynamic pulmonary hyperinflation variables and variables determined during passive expiration are shown in table 4 .
Static RS and lung PEEPi, and measured/computed $\triangle F R C$ were lower in prone versus SRBAS and SRPP. FRC was unaffected by body posture. Measured/computed EELV was lower in prone versus SRBAS. Computed $\triangle F R C$ and EELV did not differ significantly from measured $\triangle F R C$ and EELV $(\mathrm{p}=0.07-0.9)$.

\section{Expiratory airway resistance and end-expiratory $\boldsymbol{V}$}

Raw,exp was lower in prone versus SRBAS (at $V$ Ts $\geqslant 0.8 \mathrm{~L}$ ) and SRPP (at $V \mathrm{~T}=1.0 \mathrm{~L}$ ), and decreased with increasing $V \mathrm{~T}$ in all postures (fig. 4). Dynamic PEEPi and Raw,exp,EELV, were lower, and mean end-expiratory $V^{\prime}$ was higher in prone versus SRBAS and SRPP (table 4). Duration of $\triangle$ FRC-expiration was shorter in prone versus SRBAS and SRPP (table 4). Duration of the initial passive expiration phase was similar in all postures $\left(2.65^{*} \pm 0.6 \mathrm{~s}\right)$.

\section{DISCUSSION}

The main findings of the present study were that in severe chronic bronchitis, pronation reduces Raw,exp, Raw,exp,EELV and $R$ int,Lung, and increases mean end-expiratory $V^{\prime}$ versus SRBAS ( $60^{\circ}$ inclination). Following return to SRPP, pronation-induced benefits on airway resistance and mean end-expiratory $V^{\prime}$ are reversed, and dynamic pulmonary hyperinflation is augmented. Favourable effects on airway resistance were observed mainly at traditional, high $V$ Ts of $\geqslant 0.8 \mathrm{~L}$. However, Raw,exp,EELV during expiration from baseline $V \mathrm{~T}(0.6 \mathrm{~L}$ or $7.6 \pm 0.7 \mathrm{~mL} \cdot \mathrm{kg}^{-1}$ actual body weight) was also reduced, being in concordance with pronation benefits on baseline ventilation PEEPi, $\triangle F R C$, and EELV; the latter results indicate attenuation of dynamic hyperinflation. Additional pronation benefits include reductions in $\Delta R$ Lung, Estat,Lung, and shunt fraction, and $\mathrm{Pa}, \mathrm{O}_{2} / F \mathrm{I}, \mathrm{O}_{2}$ increase [1].

In the prone position, Estat,cw increases and lung parenchyma mechanics are improved (Estat,Lung/ $\Delta R$ Lung decrease) [1-3]. Results on Raw,exp, Raw,exp,EELV, and Rint,Lung, support the hypothesis of the current authors, which was based on mechanical interdependence between airway and parenchyma $[5,6]$. Prone position's reduced atelectasis and more uniform alveolar inflation [1-4] should result in an overall increased average and more homogenously distributed regional alveolar septal tension during the respiratory cycle. Such tension transmitted to airway walls [5] should result in increased airway calibre and reduced airflow resistance. The return to SRPP resulted in partial reversal of pronation effects on Estat,Lung and $\Delta R$ Lung, and consequently, neutralisation of prone position's favourable parenchyma airway calibre interaction with respect to Raw (figs 3 and 4; table 4).

Pronation results are further explained by the airway/ parenchymal hysteresis [6]. At the same lung volume, the elastic recoil pressures of the airways and parenchyma are less during expiration than during inspiration; this is known as hysteresis, and reflects viscoelastic energy dissipation [6]. If bronchial hysteresis exceeds parenchymal hysteresis, the expiratory re-establishment of pre-inspiratory bronchial elastic recoil after high $V \mathrm{~T}$ administration lags behind the expiratory re-establishment of pre-inspiratory elastic recoil of the lung parenchyma. Thus, parenchymal traction exerted on the airways prevails over airway smooth muscle tone, resulting in bronchodilation [6]. In COPD, airway hysteresis increases 

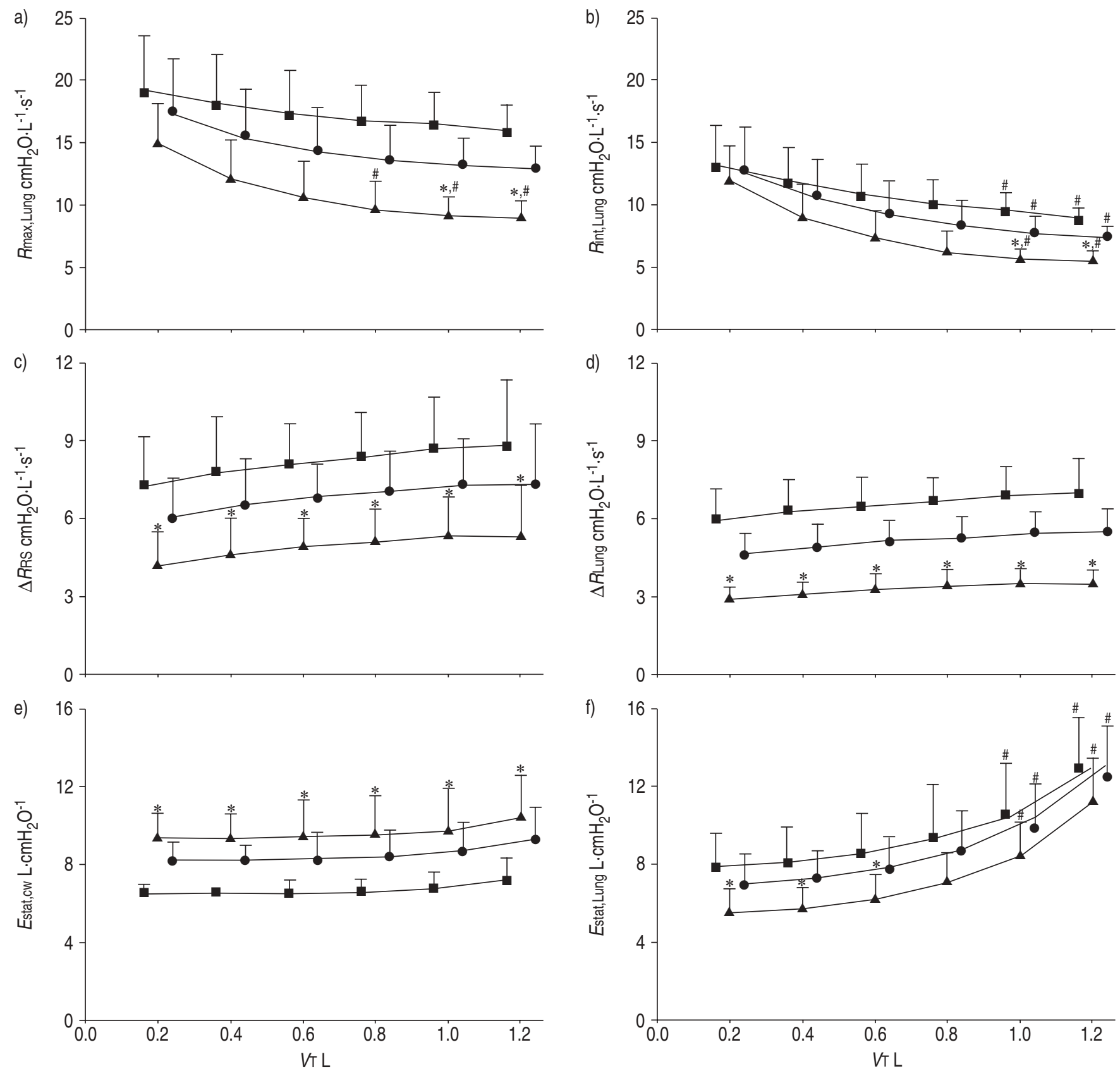

FIGURE 3. Main results on partitioned inspiratory mechanics. Data are presented as mean \pm SD for pre-prone semirecument $(\mathbf{\square})$, prone $(\mathbf{\Lambda})$ and post-prone semirecumbent ( $\bullet$ positions (a-f). Rmax,Lung: total (maximal) inspiratory resistance of the lung; Rint,Lung: interrupter (inspiratory airway) resistance of the lung; $\Delta R$ : additional resistance due to tissue stress relaxation tension and/or time constant inequality within the lung; Estat,cw: static elastance of the chest wall; $V T$ : tidal volume; Estat,Lung: static lung elastance; RS: respiratory system. *: $p<0.05$ versus baseline semirecumbent; ${ }^{*}$ : $p<0.05$ versus first value of the same body posture.

during high $V \mathrm{~T}$ breathing. Airway wall viscoelasticity is augmented [6] secondary to increased velocity of hypertophied/hyperplastic [31] airway smooth muscle shortening after high $V$ T stretching $[6,32]$. As $V$ T increases, parenchymal recoil and traction on airway walls also increases. The increasing $V$ T-induced increase in parenchymal recoil is probably enhanced in the prone position. Significant differences observed in Estat,Lung at low $V$ Ts $(\leqslant 0.6 \mathrm{~L})$, are eliminated at high $V$ Ts ( $\geqslant 0.8$ L) (fig. 3). $\Delta$ RLung results (fig. 3), suggest unchanged lung parenchymal viscoelasticity [16] with increasing $V \mathrm{~T}$ in all postures, and minimal parenchymal viscoelasticity (i.e. minimal parenchymal hysteresis) [6] in the prone position. Consequently, in the prone position, increasing airway hysteresis and minimised/stable parenchymal hysteresis with increasing $V$ T should result in enhanced parenchymainduced bronchodilation [6].

Raw,exp was measured by modifying a complex method [15]. Raw,exp,EELV was measured by dividing driving pressure by expiratory flow at EELV. Results were comparable to those 


\begin{tabular}{|c|c|c|c|}
\hline \multirow[t]{2}{*}{ TABLE 3} & \multicolumn{3}{|c|}{$\begin{array}{l}\text { Haemodynamics and gas exchange during } \\
\text { baseline ventilation }\end{array}$} \\
\hline & $\begin{array}{c}\text { BAS } \\
\text { semirecumben }\end{array}$ & Prone & $\begin{array}{c}\text { Post-prone } \\
\text { semirecumbent }\end{array}$ \\
\hline \multicolumn{4}{|l|}{ Haemodynamic variables } \\
\hline $\mathrm{HR}$ beats $\cdot \mathrm{min}^{-1}$ & $91 \pm 10$ & $84 \pm 9$ & $88 \pm 10$ \\
\hline MAP mmHg & $82 \pm 11$ & $88 \pm 12$ & $84 \pm 11$ \\
\hline CVP $\mathrm{mmHg}$ & $9 \pm 2$ & $10 \pm 4$ & $9 \pm 3$ \\
\hline MPAP $\mathrm{mmHg}$ & $22 \pm 4$ & $23 \pm 4$ & $22 \pm 4$ \\
\hline PAWP mmHg & $11 \pm 3$ & $12 \pm 3$ & $11 \pm 2$ \\
\hline $\mathrm{Cl} \mathrm{L} \cdot \mathrm{min}^{-1} \cdot \mathrm{m}^{-2}$ & $4.0 \pm 0.6$ & $4.3 \pm 0.6$ & $4.1 \pm 0.6$ \\
\hline $\mathrm{Sv}_{\mathrm{N}, \mathrm{O}_{2}} \%$ & $83 \pm 4$ & $84 \pm 4$ & $84 \pm 4$ \\
\hline$V^{\prime} \mathrm{O}_{2} \mathrm{~mL} \cdot \mathrm{min}^{-1} \cdot \mathrm{m}^{-2}$ & $142 \pm 22$ & $148 \pm 25$ & $145 \pm 24$ \\
\hline SVRI dynes $\cdot \mathrm{s} \cdot \mathrm{cm}^{-5} \cdot \mathrm{m}^{-2}$ & $1443 \pm 245$ & $1358 \pm 293$ & $1424 \pm 262$ \\
\hline PVRI dynes $\cdot \mathrm{s} \cdot \mathrm{cm}^{-5} \cdot \mathrm{m}^{-2}$ & $226 \pm 53$ & $198 \pm 49$ & $219 \pm 48$ \\
\hline \multicolumn{4}{|l|}{ Gas exchange } \\
\hline $\mathrm{Pa}, \mathrm{O}_{2} / \mathrm{Fi}_{1} \mathrm{O}_{2} \mathrm{mmHg}$ & $153 \pm 19$ & $238 \pm 25^{\star}$ & $185 \pm 21$ \\
\hline $\mathrm{Pa}, \mathrm{CO}_{2} \mathrm{mmHg}$ & $49.9 \pm 5.1$ & $46.2 \pm 2.2$ & $49.2 \pm 4.9$ \\
\hline $\mathrm{pHa}$ & $7.42 \pm 0.07$ & $7.44 \pm 0.06$ & $7.42 \pm 0.06$ \\
\hline Arterial $\mathrm{HCO}_{3} \mathrm{mEq} \cdot \mathrm{L}^{-1}$ & $31.2 \pm 3.2$ & $30.1 \pm 3.1$ & $30.8 \pm 3.2$ \\
\hline$P \mathrm{v}_{1} \mathrm{O}_{2} \mathrm{mmHg}$ & $50.9 \pm 5.5$ & $51.5 \pm 3.8$ & $51.0 \pm 5.2$ \\
\hline$P \mathrm{v}, \mathrm{CO}_{2} \mathrm{mmHg}$ & $57.0 \pm 3.9$ & $53.3 \pm 2.2$ & $56.1 \pm 3.8$ \\
\hline $\mathrm{pHv}$ & $7.37 \pm 0.05$ & $7.39 \pm 0.06$ & $7.37 \pm 0.05$ \\
\hline $\mathrm{Q}_{\mathrm{S}} / \mathrm{Q}_{\mathrm{T}}$ & $0.21 \pm 0.03$ & $0.16 \pm 0.03^{*}$ & $0.19 \pm 0.02$ \\
\hline \multicolumn{4}{|c|}{ 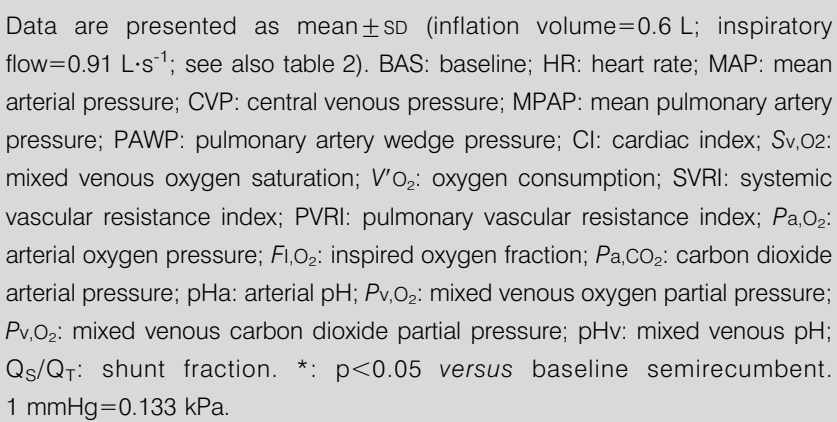 } \\
\hline
\end{tabular}

previously reported [15, 33]. In COPD, TODD et al. [33], found lung expiratory resistance of $21.01 \pm 2.88 \mathrm{cmH}_{2} \mathrm{O} \cdot \mathrm{L}^{-1} \cdot \mathrm{s}^{-1}$, being 3.5-fold higher relative to inspiratory resistance. KONDILI et al. [15], found RS expiratory resistance of $23.83 \pm 8.1 \mathrm{cmH}_{2} \mathrm{O} \cdot \mathrm{L}^{-1} \cdot \mathrm{s}^{-1}$ during $V \mathrm{~T}$ slices expired at very similar time intervals of passive expiration as reported herein (fig. 1). Raw,exp,EELV values (table 4) are comparable to recently determined RS expiratory resistance values $\left(29.02 \pm 15.60 \mathrm{cmH} \mathrm{H}_{2} \mathrm{O} \cdot \mathrm{L}^{-1} \cdot \mathrm{s}^{-1}\right)$ at $0.4-0.5 \mathrm{~L}$ above FRC [15] (compare $0.4-0.5 \mathrm{~L}$ with the semirecumbent $\triangle \mathrm{FRC}$ values reported in table 4 ).

EELV and FRC measurements with helium dilution may be affected by airway closure, which may interfere with correct mixing of helium between the anaesthesia bag and lung [26]. The current authors employed high VTs (1.0-1.5 L), which resulted in $\mathrm{PL}>20 \mathrm{cmH}_{2} \mathrm{O}$ and probable re-opening of closed airways [26, 34, 35]. Low respiratory rates were also used, which resulted in a prolonged expiratory time of $\sim 12 \mathrm{~s}$, in order to augment expiratory helium mixing between anaesthesia bag and lung and minimise helium trapping.

\begin{tabular}{|c|c|c|c|c|}
\hline \multirow[t]{2}{*}{ TABLE 4} & \multicolumn{4}{|c|}{$\begin{array}{l}\text { Variables reflecting dynamic pulmonary } \\
\text { hyperinflation and variables determined during } \\
\text { passive expiration from end-expiratory lung } \\
\text { volume (EELV) to functional residual capacity } \\
\text { (FRC) }\end{array}$} \\
\hline & & $\begin{array}{c}\text { Baseline } \\
\text { semirecumbent }\end{array}$ & Prone & $\begin{array}{c}\text { Post-prone } \\
\text { semirecumbent }\end{array}$ \\
\hline \multicolumn{2}{|c|}{ EELV computed L } & $5.65 \pm 0.65$ & $4.92 \pm 0.49^{\#}$ & $5.52 \pm 0.59$ \\
\hline \multicolumn{2}{|c|}{ EELV measured L } & $5.71 \pm 0.65$ & $4.94 \pm 0.49^{\#}$ & $5.56 \pm 0.60$ \\
\hline \multicolumn{2}{|c|}{ FRC measured $L$} & $5.24 \pm 0.63$ & $4.60 \pm 0.47$ & $5.13 \pm 0.57$ \\
\hline \multicolumn{2}{|c|}{$\triangle F R C$ measured $L$} & $0.47 \pm 0.04$ & $0.35 \pm 0.03^{\bullet, 5}$ & $0.44 \pm 0.03$ \\
\hline \multicolumn{2}{|c|}{$\Delta F R C$ computed $L$} & $0.41 \pm 0.04$ & $0.32 \pm 0.03^{\bullet, 5}$ & $0.39 \pm 0.03$ \\
\hline \multicolumn{2}{|c|}{ Static PEEPi,RS $\mathrm{cmH}_{2} \mathrm{O}$} & $8.9 \pm 1.7$ & $6.7 \pm 1.1^{\#,+}$ & $8.2 \pm 1.2$ \\
\hline \multicolumn{2}{|c|}{ Static PEEPi,Lung $\mathrm{cmH}_{2} \mathrm{O}$} & $7.8 \pm 1.1$ & $5.4 \pm 0.6^{\#,+}$ & $7.1 \pm 0.7$ \\
\hline \multicolumn{2}{|c|}{ Static PEEPi,cw $\mathbf{c m H}_{2} \mathrm{O}$} & $1.1 \pm 0.6$ & $1.3 \pm 0.6$ & $1.1 \pm 0.6$ \\
\hline \multicolumn{2}{|c|}{$\begin{array}{l}\text { Expiratory Raw at EELV } \\
\mathrm{cmH}_{2} \mathrm{O} \cdot \mathrm{L}^{-1} \cdot \mathrm{s}^{-1}\end{array}$} & $31.6 \pm 2.6$ & $18.3 \pm 1.4^{\oplus, \S}$ & $28.4 \pm 1.9$ \\
\hline \multicolumn{2}{|c|}{$\begin{array}{l}\text { Dynamic PEEPi } \\
\qquad \mathrm{cmH}_{2} \mathrm{O} \cdot \mathrm{L}^{-1} \cdot \mathrm{s}^{-1}\end{array}$} & $3.0 \pm 0.3$ & $2.3 \pm 0.3^{\bullet++}$ & $2.9 \pm 0.3$ \\
\hline \multicolumn{2}{|c|}{$\begin{array}{l}\text { Mean end-expiratory flow } \\
\mathrm{mL} \cdot \mathrm{s}^{-1}\end{array}$} & $47.9 \pm 4.0$ & $63.9 \pm 4.2^{\bullet, 5}$ & $51.2 \pm 4.7$ \\
\hline \multicolumn{2}{|c|}{ Time of $\Delta F R C$ expiration $s$} & $24.1 \pm 3.3$ & $11.5 \pm 1.6^{\bullet, 5}$ & $21.1 \pm 2.9$ \\
\hline
\end{tabular}

Data are presented as mean \pm SD. $\triangle F R C$ : change in FRC; PEEPi: intrinsic positive end-expiratory pressure; RS: respiratory system; cw: chest wall; Raw: airway resistance. Measured EELV/FRC refers to helium dilution determinations; measured $\triangle F R C$ refers to volume determination carried out during passive exhalation from EELV to FRC; computed $E E L V=$ measured FRC plus measured $\triangle \mathrm{FRC}$; computed $\triangle \mathrm{FRC}=$ measured $\mathrm{EELV}$-measured FRC. ${ }^{\#}: \mathrm{p}<0.05$ versus baseline semirecumbent; ${ }^{\circ}: p<0.01$ versus baseline semirecumbent; ${ }^{+}: p<0.05$ versus post-prone semirecumbent; ${ }^{\text {s. }} p<0.01$ versus post-prone semirecumbent.

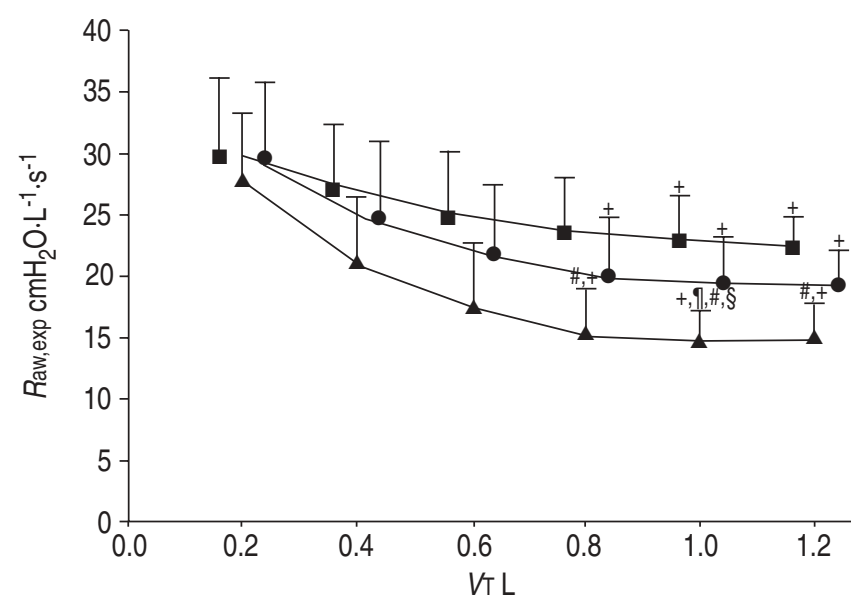

FIGURE 4. Results on expiratory airway resistance (Raw,exp). Data are presented as mean \pm SD for pre-prone semirecument $(\boldsymbol{\square})$, prone $(\mathbf{\Lambda})$ and postprone semirecumbent $(\bullet)$ positions. \#: $p<0.05$ versus baseline semirecumbent; $p<0.05$ versus post-prone semirecumbent; ${ }^{+}: p<0.05$ versus first sequential value of the same body posture; ${ }^{\text {s. }} \mathrm{p}<0.05$ versus second sequential value of the same body posture. 
This was probably achieved because $\triangle F R C$ (EELV-portion reflecting trapped volume) [1, 16] was estimated with acceptable accuracy with the helium dilution technique. Indeed, helium dilution-computed and measured $\triangle F R C$ did not differ significantly (table 4). Other limitations of the helium dilution technique are related to FRC reduction during anaesthesia and loss of gas volume due to continuing gas exchange [26].

\section{Implications for clinical practice and further research}

Severe COPD is characterised by elevated Raw and PEEPi [10, 11]. During controlled mechanical ventilation, adverse effects of PEEPi and dynamic hyperinflation include haemodynamic compromise and risk of barotrauma [36]. Ventilatory management goals should include minimisation of dynamic hyperinflation, Raw, and risk of ventilator-associated lung injury. Use of helium oxygen mixtures and external positive end-expiratory pressure not exceeding PEEPi have been advocated [37]. Other, recent textbook recommendations include use of low VTs (5$7 \mathrm{~mL} \cdot \mathrm{kg}^{-1}$ predicted body weight) at rates of 20-24 cycles."' $\min ^{-1}[38]$. The importance of adequate expiratory time to allow for effective lung deflation cannot be overemphasised. Recently, GAINNIER et al. [39], employed VTs of 7-8 $\mathrm{mL} \cdot \mathrm{kg}^{-1}$ actual body weight at rates of $14 \pm 2.3 \mathrm{cycles} \cdot \mathrm{min}^{-1}$. The present authors employed similar baseline $V \mathrm{~T}$ at relatively high rates of $18.0 \pm 0.7$ cycles $\cdot \mathrm{min}^{-1}$; however, relative to the study by GAINNIER et al. [39], the (baseline ventilation) expiratory time was comparable ( $\sim 3 \mathrm{~s})$ secondary to $40 \%$ higher inspiratory flow (similar inspiratory flow has also been recently used [37]), whereas $\mathrm{Pa}_{\mathrm{a}} \mathrm{CO}_{2}$ and $\mathrm{pH}$ (table 3) were also comparable. Despite this argumentation, it is likely that the baseline ventilation settings in the current study could be further optimised according to the above-mentioned ventilation goals. Therefore, based on the results of the present study, the authors recommend the use of the prone position in severe COPD patients who continue to experience adverse effects of PEEPi and dynamic hyperinflation, even during optimised ventilation in the semirecumbent position.

Reduction in Raw and PEEPi, and attenuation of dynamic hyperinflation, indicate reduced respiratory workload in prone position. Pulmonary hyperinflation and increased EELV result in diminution of the diaphragm's apposition zone, shortened operating length of diaphragmatic muscle fibres, and reduced diaphragmatic mechanical effectiveness during spontaneous inspiration [40]. Severe COPD patients failing to wean from mechanical ventilation experience increased respiratory workload $[10,11]$. Consequently, further investigation is warranted to determine whether pronation benefits demonstrated herein can be maintained during partial ventilatory support and/or spontaneous breathing.

\section{Conclusion}

Pronation of anaesthetised, volume-controlled mode ventilated, severe chronic bronchitis patients reduces airway resistance and attenuates dynamic hyperinflation. This is probably attributable to improved parenchyma mechanics inducing an increase in airway calibre during the respiratory cycle.

\section{APPENDIX 1: FORMULAS USED TO DERIVE HAEMODYNAMIC AND GAS EXCHANGE VARIABLES $[41,42]$}

1. Cardiac index $=\mathrm{CO} / \mathrm{BSA}$

2. Systemic vascular resistance index $=(\mathrm{MAP}-\mathrm{CVP}) \times$ $80 \times \mathrm{CI}^{-1}$

3. Pulmonary vascular resistance index $=($ MPAP-PAWP $) \times$ $80 \times \mathrm{CI}^{-1}$

4. Oxygen consumption per $\mathrm{m}^{2} \mathrm{BSA}=\mathrm{CI} \times 1.36 \times \mathrm{Hgb} \times$ $\left(\mathrm{SaO}_{2}-\mathrm{SvO}_{2}\right)$

5. Respiratory quotient $=(\mathrm{FEY}$ of carbohydrate intake $)$ $1.0+($ FEY of protein intake $) \times 0.8+($ FEY of lipid intake $) \times$ 0.7 [43]

6. Alveolar $\mathrm{PO}_{2}=P \mathrm{i}, \mathrm{O}_{2}-P A, \mathrm{CO}_{2} \times\left[F \mathrm{I}, \mathrm{O}_{2}-\left(1-F \mathrm{I}, \mathrm{O}_{2}\right) \times \mathrm{R}^{-1}\right]$; $P \mathrm{i}, \mathrm{O}_{2}=F \mathrm{I}, \mathrm{O}_{2} \times(\mathrm{PB}-47) ; P \mathrm{~A}, \mathrm{CO}_{2} \sim \mathrm{Pa}_{1}, \mathrm{CO}_{2}$

7. $\mathrm{O}_{2}$ content of blood $=\mathrm{Hgb} \times 1.36 \times \mathrm{SO}_{2} \times 10-1+0.003 \times \mathrm{PO}_{2}$

8. Shunt fraction $=\left(\mathrm{C}_{\mathrm{c}}, \mathrm{O}_{2}-\mathrm{Ca}_{\mathrm{a}} \mathrm{O}_{2}\right) \times\left(\mathrm{C}_{\mathrm{c}}, \mathrm{O}_{2}-\mathrm{C}_{\mathrm{v}}, \mathrm{O}_{2}\right)-1$.

CO: cardiac output $\left(\mathrm{L} \cdot \mathrm{min}^{-1}\right)$; BSA: body surface area $\left(\mathrm{m}^{2}\right)$; MAP: mean arterial pressure $(\mathrm{mmHg})$; CVP: central venous pressure $(\mathrm{mmHg})$; 80: transformation factor of Wood units $\left(\mathrm{mmHg} \cdot \mathrm{L}^{-1} \cdot \mathrm{min}\right)$ to standard metric units $\left(\right.$ dynes $\left.\cdot \mathrm{s} \cdot \mathrm{cm}^{-5}\right)$; CI: cardiac index $\left(\mathrm{L} \cdot \mathrm{min}^{-1} \cdot \mathrm{m}^{-2}\right)$; MPAP: mean pulmonary artery pressure (mmHg); PAWP: pulmonary artery wedge pressure $(\mathrm{mmHg}) ; \mathrm{Hgb}:$ haemoglobin concentration in $\mathrm{g} \cdot \mathrm{L}^{-1} ; 1.36: \mathrm{O}_{2}$ combining power of $1 \mathrm{~g}$ of haemoglobin $(\mathrm{mL}) ; \mathrm{Sa}_{2} \mathrm{O}_{2}$ : arterial $\mathrm{O}_{2}$ saturation; $\mathrm{S}_{\mathrm{v}} \mathrm{O}_{2}$ : mixed venous $\mathrm{O}_{2}$ saturation; $\mathrm{FEY}$ : fractional energy yield relative to total of prescribed nutritional support; $\mathrm{Si}_{\mathrm{i}} \mathrm{O}_{2}$ : inspired $\mathrm{O}_{2}$ partial pressure $(\mathrm{mmHg})$; $\mathrm{R}$ : respiratory quotient; $P \mathrm{~B}$ : barometric pressure $(\mathrm{mmHg}) ; 47$ : water saturated vapour pressure at $37^{\circ} \mathrm{C}(\mathrm{mmHg}) ; 0.003: \mathrm{O}_{2}$ solubility coefficient at $37^{\circ} \mathrm{C}\left(\mathrm{mL} \cdot \mathrm{dL}^{-1} \cdot \mathrm{mmHg}\right) ; \mathrm{PO}_{2}: \mathrm{O}_{2}$ partial pressure $(\mathrm{mmHg}) ; \mathrm{C}_{\mathrm{c}, \mathrm{O}_{2}} / \mathrm{Ca}_{2} \mathrm{O}_{2} / \mathrm{C}_{\mathrm{v}}, \mathrm{O}_{2}, \mathrm{O}_{2}$ content in end-capillary/ arterial/mixed-venous blood, respectively.

$1 \mathrm{mmHg}=0.133 \mathrm{kPa}$.

\section{APPENDIX 2: INSPIRATORY MECHANICAL VARIABLES}

For the respiratory system, chest wall and lung the following inspiratory mechanical variables were determined: 1) maximal, interrupter, and additional resistances, computed as respective $P \max -P_{2}, P_{\max }-P_{1}$ and $P_{1}-P_{2}$ differences divided by the preceding inspiratory flow; and 2) dynamic and static elastances, computed as respective $P_{1}$-static PEEPi and $P_{2}-$ static PEEPi differences divided by the administered $V$ T. Lung interrupter resistance reflects "ohmic" airway resistance; lung additional resistance reflects lung tissue stress relaxation tension and time constant inequality.

\section{REFERENCES}

1 Mentzelopoulos SD, Zakynthinos SG, Roussos C, Tzoufi MJ, Michalopoulos AS. Prone position improves lung mechanical behaviour and enhances gas exchange efficiency in mechanically ventilated chronic obstructive pulmonary disease patients. Anesth Analg 2003; 96: 1756-1767. 
2 Pelosi P, Tubiolo D, Mascheroni D, et al. Effects of the prone position on respiratory mechanics and gas exchange during acute lung injury. Am J Respir Crit Care Med 1998; 157: 387-393.

3 Albert RK, Hubmayr RD. The prone position eliminates compression of the lungs by the heart. Am J Respir Crit Care Med 2000; 161: 1660-1665.

4 Mure M, Domino KB, Lindahl SG, Hlastala MP, Altemeier WA, Glenny RW. Regional ventilation-perfusion distribution is more uniform in the prone position. J Appl Physiol 2000; 88: 1076-1083.

5 Hopin FG Jr. Sources of lung recoil. In: Milic-Emili J, ed. Eur Respir Mon 1999; pp. 33-53.

6 Brusasco V, Pellegrino P, Rodarte JR. Airway mechanics. In: Milic-Emili J, ed. Eur Respir Mon 1999; pp. 68-91.

7 Mannino DM. COPD: Epidemiology, prevalence, morbidity and mortality, and disease heterogeneity. Chest 2002; 121: Suppl. 5, 121S-126S.

8 American Thoracic Society. Standards for the diagnosis and care of patients with chronic obstructive pulmonary disease. Am J Respir Crit Care Med 1995; 152: Suppl. 5, 77S-121S.

9 American Thoracic Society. Lung function testing: selection of reference values and interpretive strategies. Am Rev Respir Dis 1991; 144: 1208-1218.

10 Purro A, Appendini L, De Gaetano A, Gudjonsdottir M, Donner CF, Rossi A. Physiologic determinants of ventilator dependence in long-term mechanically ventilated patients. Am J Respir Crit Care Med 2000; 161: 1115-1123.

11 Appendini L, Purro A, Patessio A, et al. Partitioning of inspiratory muscle workload and pressure assistance in ventilator-dependent COPD patients. Am J Respir Crit Care Med 1996; 154: 1301-1309.

12 Hankinson JL, Odencrantz JR, Fedan JB. Spirometric reference values from a sample of the general U.S. population. Am J Respir Crit Care Med 1999; 159: 178187.

13 Dewan NA, Rafique S, Kanwar B, et al. Acute exacerbation of COPD: factors associated with poor treatment outcome. Chest 2000; 117: 662-671.

14 Prechter GC, Nelson SB, Hubmayr RD. The ventilatory recruitment threshold for carbon dioxide. Am Rev Respir Dis 1990; 141: 758-764.

15 Kondili E, Alexopoulou C, Prinianakis G, Xirouchaki N, Georgopoulos D. Pattern of lung emptying and expiratory resistance in mechanicaly ventilated patients with chronic obstructive pulmonary disease. Intensive Care Med 2004; 30: 1311-1318.

16 Guérin C, Coussa ML, Eissa NT, et al. Lung and chest wall mechanics in mechanically ventilated COPD patients. J Appl Physiol 1993; 74: 1570-1580.

17 Baydur A, Behrakis PK, Zin WA, Jaeger M, Milic-Emili J. A simple method for assessing the validity of the esophageal balloon technique. Am Rev Respir Dis 1982; 126: 788-791.

18 Ranieri VM, Brienza N, Santostasi S, et al. Impairment of lung and chest wall mechanics in patients with acute respiratory distress syndrome. Role of abdominal distention. Am J Respir Crit Care Med 1997; 156: 1082-1091.

19 Diehl JL, Lofaso F, Deleuze P, Similowski T, Lemaire F, Brochard L. Clinically relevant diaphragmatic dysfunction after cardiac operations. Ann Thorac Surg 1994; 107: 487-498.

20 Johnson B, Richard JC, Straus C, Mancebo J, Lemaire F, Brochard L. Presssure-volume curves and compliance in acute lung injury. Evidence of recruitment above the lower inflection point. Am J Respir Crit Care Med 1999; 159: 1172-1178.

21 Suter PM. Does the advent of (new) low tidal volumes bring the (old) sigh back to the intensive care unit? Anesthesiology 2002; 96: 783-784.

22 Tantucci C, Corbeil C, Chasse M, Braidy J, Matar N, MilicEmili J. Flow resistance in patients with chronic obstructive pulmonary disease in acute respiratory failure. Am Rev Respir Dis 1991; 144: 384-389.

23 Maltais F, Reissmann H, Navalesi P, et al. Comparison of static and dynamic measurements of intrinsic PEEP in mechanically ventilated patients. Am J Respir Crit Care Med 1994; 150: 1318-1324.

24 Pelosi P, Croci M, Callapi E, et al. Prone positioning improves pulmonary function in obese patients during general anesthesia. Anesth Analg 1996; 83: 578-583.

25 Pelosi P, Croci M, Calappi E, et al. The prone positioning during general anesthesia minimally affects respiratory mechanics while improving functional residual capacity and increasing oxygen tension. Anesth Analg 1995; 80: 955-960.

26 Pelosi P, Croci M, Ravagnan I, et al. Respiratory system mechanics in sedated, paralyzed, morbidly obese patients. J Appl Physiol 1997; 83: 811-818.

27 Valta P, Corbeil C, Lavoie R, et al. Detection of expiratory flow limitation during mechanical ventilation. Am J Respir Crit Care Med 1994; 50: 1311-1317.

28 Koutsoukou A, Armaganidis A, Stavrakaki-Kallergi C, et al. Expiratory flow limitation and intrinsic positive endexpiratory pressure at zero positive end-expiratory pressure in patients with adult respiratory distress syndrome. Am J Respir Crit Care Med 2000; 161: 1590-1596.

29 West JB. Ventilation. In: West JB, ed. Pulmonary pathophysiology- the essentials. 4th Edn. Baltimore, Williams \& Wilkins, 1992; pp. 3-18.

30 Milic-Emili J, Mead J, Turner JM. Topography of esophageal pressure as a function of posture in man. J Appl Physiol 1964; 19: 212-216.

31 Saetta M, Turato G. Lung structure and function. In: MilicEmili J, ed. Eur Respir Mon 1999; pp. 1-19.

32 Mitchell RW, Rabe KF, Magnussen H, Leff AR. Passive sensitization of human airways induces myogenic contractile responses in vitro. J Appl Physiol 1997; 83: 12761281.

33 Todd OM, Pellegrino R, Brusasco V, Rodarte JR. Measurement of pulmonary resistance and dynamic compliance with airway obstruction. J Appl Physiol 1998; 85: 1982-1988.

34 Don HF, Wahba WM, Craig DB. Airway closure, gas trapping, and the functional residual capacity during anesthesia. Anesthesiology 1972; 36: 533-539.

35 Glaister DH, Schroter RC, Sudlow MF, Milic-Emili J. Transpulmonary pressure gradient and ventilation distribution in excised lungs. Respir Physiol 1973; 17: 347-354.

36 Tuxen DV. Detrimental effects of positive end-expiratory pressure during controlled mechanical ventilation of 
patients with severe airflow obstruction. Am Rev Respir Dis 1989; 140: 5-9.

37 Jolliet $\mathrm{P}$, Watremez C, Roeseler J, et al. Comparative effects of helium-oxygen and external positive end-expiratory pressure on respiratory mechanics, gas exchange, and ventilation-perfusion relationships in mechanically ventilated patients with chronic obstructive pulmonary disease. Intensive Care Med 2003; 29: 1442-1450.

38 Schmidt GA, Hall JB, Wood LDH. Ventilatory Failure. In: Murray JF, Nadel JA, Mason RJ, Boushey HA, eds. Textbook of Respiratory Medicine. 3rd Edn. Philadelphia, WB Saunders, 2000; pp. 2443-2471.

39 Gainnier M, Arnal JM, Gerbaux P, Donati S, Papazian L, Sainty JM. Helium-oxygen reduces work of breathing in mechanically ventilated patients with chronic obstructive pulmonary disease. Intensive Care Med 2003; 29: 1666-1670.

40 Vassilakopoulos T, Zakynthinos S, Roussos C. Muscle Function. In: Marini JJ, Slutsky AS, eds. Physiological Basis of Ventilatory Support. New York, Dekker, 1998; pp. 103153.

41 Mark JB, Slaughter TF, Reves JG. Cardiovascular monitoring. In: Miller RD, ed. Anaesthesia. 5th Edn. New York, Churchill Livingstone, 2000; pp. 1117-1230.

42 Moon ME, Camporesi EM. Respiratory monitoring. In: Miller RD, ed. Anaesthesia. 5th Edn. New York, Churchill Livingstone, 2000; pp. 1255-1296.

43 Marino PL. Nutrient and energy requirements. In: Marino PL, ed. The ICU book. 2nd Edn. Baltimore, Williams \& Wilkins, 1997; pp. 721-736. 